\title{
Gli1 contributes to cellular resistance to cisplatin through altered cellular accumulation of the drug
}

\author{
LAUREN AMABLE ${ }^{1}$, JASON FAIN $^{2}$, ELAINE GAVIN $^{2}$ and EDDIE REED ${ }^{1}$ \\ ${ }^{1}$ National Institute on Minority Health and Health Disparities, National Institutes of Health, Bethesda, MD 20892; \\ ${ }^{2}$ Mitchell Cancer Institute, University of South Alabama, Mobile, AL 36604, USA
}

Received August 1, 2013; Accepted December 30, 2013

DOI: 10.3892/or.2014.3257

\begin{abstract}
Cellular resistance to platinum anticancer compounds is governed by no less than two molecular processes; DNA repair and cellular accumulation of drug. Gli1 is an upstream regulator of nucleotide excision repair, effecting this process through c-jun. We, therefore, investigated whether Gli1 plays a role in cellular accumulation of cisplatin. Using a Gli1-specific shRNA, we explored the role of Gli1 in the cellular accumulation and efflux of cisplatin, in cisplatinresistant A2780-CP70 human ovarian cancer cells. When Gli1 is inhibited, cellular uptake of cisplatin was approximately $33 \%$ of the level of uptake under control conditions. When Gli1 is inhibited, cellular efflux of cisplatin was completely abrogated, over a $12-\mathrm{h}$ period of observation. We assayed nuclear lysates from these cells, for the ability to bind the DNA sequence that is the Gli-binding site (GBS) in the 5'UTR for each of five known cisplatin transmembrane transporters. Four of these transporters are active in cisplatin uptake; and, one is active in cisplatin efflux. In each case, nuclear lysate from A2780-CP70 cells binds the GBS of the respective cisplatin transport gene. We conclude that Glil plays a strong role in total cellular accumulation of cisplatin in these cells; and, that the combined effects on cellular accumulation of drug and on DNA repair may indicate a role for Gli1 in protecting cellular DNA from lethal types of DNA damage.
\end{abstract}

\section{Introduction}

Cancer stem cells have the phenotype of a high level of resistance to a range of anticancer agents, including platinum compounds. Maintenance of cancer stem cells is dependent on the Hedgehog $(\mathrm{Hh})$ pathway. The $\mathrm{Hh}$ role in platinum resis-

Correspondence to: Dr Eddie Reed, National Institute on Minority Health and Health Disparities, National Institutes of Health, 3 Center Drive, Bethesda, MD 20892, USA

E-mail: eddie.reed@nih.gov

Key words: cisplatin resistance, Gli1, cisplatin transport, ovarian cancer, DNA repair, DNA adduct tance is related in part to the positive transcription factor Gli1 and its role in the regulation of c-jun and ERCC1 $(1,2)$. The knockdown of Glil using shRNA results in a series of events: the c-jun phosphorylation pattern changes from the anti-apoptotic Ser63/73 to the pro-apoptotic Thr91/93; c-jun-dependent DNA repair genes are not upregulated; cisplatin-DNA adduct repair is markedly reduced; and cells are sensitized to cisplatin by a factor of six (1).

Cellular resistance to cisplatin is multifactorial (3-5). One of the factors that controls the level of cisplatin resistance is altered cellular accumulation of drug (4-7). Cellular accumulation of cisplatin is regulated by several processes, including passive diffusion, carrier-mediated uptake and carrier-mediated efflux. In the excellent review by Hall et al (8), the five known mechanisms of cisplatin uptake and the four known mechanisms of cisplatin efflux are summarized. Uptake of cisplatin is mediated by: i) passive diffusion; ii) a protein gate, linked to the $\mathrm{Na}^{+} \mathrm{K}^{+}$-ATPase pump; iii) fluid phase endocytosis; iv) organic cation transporter (OCT) 1-3 proteins; and v) copper transporter CTR1 and CTR2 proteins. Efflux is mediated by: i) melanosomes; ii) ATP7B dependent vesicles; iii) ATP7A protein; and iv) MRP1-5 proteins.

Uptake of cisplatin is mediated by proteins that have multiple transport functions. Specifically OCT1, OCT2 and OCT3 function as transporters of organic cations, monoamine neurotransmitters, xenobiotics and various drugs. OCT1, OCT2 and OCT3 transport cisplatin and oxaliplatin. Uptake of cisplatin is also mediated by two copper transporters: CTR1 and CTR2. CTR1 and CTR2 normally function for copper influx. Both of these CTR transporters have been shown to transport cisplatin and carboplatin, but CTR1 is additionally involved in the transport of oxaliplatin.

Efflux of cisplatin occurs through the ATPase copper transporters ATP7A and ATP7B. The ATP7A and ATP7B transporters are both involved in copper sequestration and efflux and transport both cisplatin and carboplatin.

In our examination of the molecular sequences of the genes discussed above, we found potential Gli-binding sites (GBS) in five of these genes: OCT1, OCT2, OCT3, CTR1 and ATP7B. These potential Gli binding sites are given in Fig. 2A. In the present study, we explore whether inhibition of Gli1 has any effect on total cellular accumulation of cisplatin in A2780-CP70 cisplatin-resistant human ovarian cancer cells. We also examined whether there is any evidence that the Gli- 
binding sites for these genes, would be recognized by nuclear lysates from this cell line. Our results suggest that Gli1 may play a strong role in modulating total cellular accumulation of cisplatin in these cells, through altered drug uptake and altered drug efflux.

\section{Materials and methods}

Cells. The cisplatin resistant A2780-CP70 ovarian cancer cells were used in all experiments. Cells were retrieved from a frozen stock and experiments were performed between passages 5 and 30. Cells were cultured in RPMI-1640 media (Gibco/Invitrogen, Carlsbad, CA, USA) supplemented with $10 \%$ fetal bovine serum (Gibco), L-glutamine (Gibco), insulin (Sigma-Aldrich, St. Louis, MO, USA) and penicillin/streptomycin (Gibco). During active experiments, cells were carried in media without penicillin/streptomycin.

Whole cell platinum analysis. Cells were treated under two experimental conditions. One set of cells were treated with anti-Gli1 shRNA at an $\mathrm{IC}_{20}$ dose for $24 \mathrm{~h}$, prior to treatment with cisplatin. Glil was targeted for degradation using shRNA specific for Gli1 (1). Control cells were treated with scrambled shRNA at the same micromolar dose for $24 \mathrm{~h}$, prior to cisplatin treatment.

A2780-CP70 cells were seeded at $2 \times 10^{6}$ in a $10-\mathrm{cm}^{2}$ dish. The following morning, cells were transfected with Glil or scrambled shRNA using Lipofectamine according to the manufacturer's instructions (Invitrogen). Twenty-four hours later cells were treated with $30 \mu \mathrm{M}$ cisplatin for $1 \mathrm{~h}$, the $\mathrm{IC}_{50}$ dose when cisplatin is used alone. Cisplatin-containing media was then removed and plates were washed with cold PBS. The zero hour time point was immediately after the 1-h cisplatin dose. Cells were harvested by trypsinization and collected.

For the 12-h time-point, cisplatin-containing media was removed after the 1-h drug exposure. Cells were washed with PBS and fresh cisplatin-free media was then added. Cells were collected by trypsinization $12 \mathrm{~h}$ later. Cells were harvested by centrifugation and counted by trypan blue dye exclusion assays. The collected cell pellets were stored at $-80^{\circ} \mathrm{C}$ until analysis.

Cell pellets were prepared for atomic absorption spectroscopy (AAS) analysis by wet ashing as previously described (9). Briefly, cell pellets were treated with $0.5 \mathrm{ml}$ nitric acid and incubated in a water bath at $100^{\circ} \mathrm{C}$ for $5 \mathrm{~min}$. Polypropylene $15 \mathrm{ml}$ conical tubes were used. Samples were cooled to room temperature under running water. Hydrogen peroxide, $0.5 \mathrm{ml}$ of $30 \%$, was added to the tube and re-submerged into the water bath at $100^{\circ} \mathrm{C}$ for $5 \mathrm{~min}$. Samples were again cooled to room temperature before analysis by AAS.

Platinum in each sample was measured by AAS using a Perkin Elmer 600 AAnalyst AAS machine with Zeeman background correction and a platinum lamp (Perkin-Elmer, Walthan, MA, USA). Platinum standards were used to generate a standard curve. Total platinum per $1 \times 10^{6}$ cells was determined based on the cell counts and the total platinum in each sample. Total cellular platinum per million cells at $0 \mathrm{~h}$, was compared with the total platinum level per million cells at $12 \mathrm{~h}$.
Binding site search. Genomic sequences containing $10 \mathrm{kB}$ upstream of the translation start site were obtained from Ensembl (Www.ensembl.org) for the following transporter genes: ATP7A (ATP7A-001), ATP7B (ATPB-001), CTR1 (SLC31A1-001), CTR2 (SLC31A2-001), OCT1 (SLC22A1001), OCT2 (SLC22A2-001) and OCT3 (SLC22A3-001). The following known Gli-binding sites were used in the search parameters: GAGCAGCCA, GACGACCCC, GGCCCCCCA, GACCGCCCC, AACCAACCCC, GTCCTCCCA, GACCAC CCA (10), GAACACCCA, CACCACCCA and GACCACCAA (11). A pairwise BLAST (basic local alignment search tool, bl2seq, http://blast.ncbi.nlm.nih.gov/Blast.cgi) was performed to compare the promoter region with each GBS. The parameters of the pairwise BLAST were kept at the default setting except for the word size was changed from 11 to 7 . Activator protein 1 (AP1) binding sites were searched in each transporter promoter using the following sequence TGAGTCA $(12,13)$ and keeping in the same pairwise BLAST search parameters.

Electrophoretic mobility shift assays (EMSAs). The putative Gli-binding sites found in the promoters in the listed transporters were synthesized as DNA oligonucleotides and the reverse compliment containing a 5 ' biotin were obtained for the following transporters: ATP7A (AATCGTATGAACACC CATATACCCA), CTR2 (AAATAAATTGGGTGGTCAGA GTGGC), OCT1 (TCAGCCCTTGGGTGGTCGATGGGAC, GTCCATGCTTGGTGGTCTTTTACCA), OCT2(TAAGTTC CTGGCTGCTCGGGGCACT) and OCT3 (AACCGCAA TCCTCCCAAGGCCTTG, TCTGGGGGTGGGTGGTGG TTTTATC) (Integrated DNA Technologies, Coralville, IA, USA). Each oligonucleotide was resuspended in Milli-Q-water at a final concentration of $100 \mu \mathrm{M}$. Double stranded DNA (dsDNA) probes were generated by adding $1 \mu \mathrm{M}$ of the forward and reverse compliment oligonucleotides in annealing buffer (10 mM Tris, $1 \mathrm{mM}$ EDTA, $50 \mathrm{mM} \mathrm{NaCl}, \mathrm{pH}$ 8.0) and heated to $95^{\circ} \mathrm{C}$ and cooled to room temperature at a rate of $1{ }^{\circ} \mathrm{C} / \mathrm{min}$.

Nuclear lysate was prepared from A2780-CP70 as previously described (1). Protein concentration was determined using BCA kit (Thermo Pierce, Rockford, IL, USA). The EMSA DNA-binding reaction was carried out using LightShift Chemiluminescent EMSA kit (Thermo Pierce). Each reaction consisted of $20 \mathrm{fmol}$ of biotin labeled dsDNA, $1 \mu \mathrm{g}$ poly (dI-dC), $20 \mu \mathrm{g}$ nuclear lysate in a $20 \mu \mathrm{l}$ of reaction buffer $(40 \mathrm{mM}$

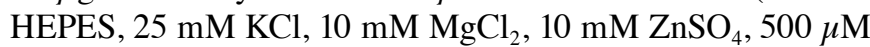
EDTA, $10 \%$ glycerol, $\mathrm{pH}$ 7.8). The DNA-binding reaction was incubated on ice for $30 \mathrm{~min}$ and $5 \mu \mathrm{l}$ of loading buffer was added. Samples were separated on a $6 \%$ native polyacrylamide gel, and transferred to a positively charged PVDF membrane (BrightStar Plus; Ambion, Austin, TX, USA). The dsDNA biotin probe was visualized using the reagents of the kit.

\section{Results}

Anti-Glil shRNA reduces cisplatin influx and shuts down cisplatin efflux. We first assessed total cellular platinum in these cells, after pretreatment with anti-Gli1 shRNA for $24 \mathrm{~h}$, followed by cisplatin treatment for $1 \mathrm{~h}$. This was compared to pretreatment for $24 \mathrm{~h}$ with scrambled shRNA control followed by cisplatin treatment for $1 \mathrm{~h}$, at the same cisplatin dose. As shown in Fig. 1A and B, under control conditions, 
A

\begin{tabular}{|c|c|c|}
\hline & Control $(n=4)$ & shGli1 $(n=4)$ \\
\hline \multicolumn{3}{|l|}{$\begin{array}{l}\text { Total cellular } \\
\text { platinum }\end{array}$} \\
\hline TO & $\begin{array}{l}3.75 \mathrm{ng} \text { platinum } / 10^{6} \\
\pm 3.23\end{array}$ & $\begin{array}{l}1.58 \mathrm{ng} \text { platinum } / 10^{6} \\
\pm 0.71\end{array}$ \\
\hline T12 & $\begin{array}{l}1.25 \mathrm{ng} \text { platinum } / 10^{6} \\
\pm 1.39\end{array}$ & $\begin{array}{l}1.66 \mathrm{ng} \text { platinum } / 10^{6} \\
\pm 2.15\end{array}$ \\
\hline Amount effluxed & $\begin{array}{l}2.5 \mathrm{ng} \text { platinum } / 10^{6} \\
\pm 3.64\end{array}$ & $\begin{array}{l}-0.08 \mathrm{ng} \text { platinum } \\
/ 10^{6} \pm 1.98\end{array}$ \\
\hline
\end{tabular}

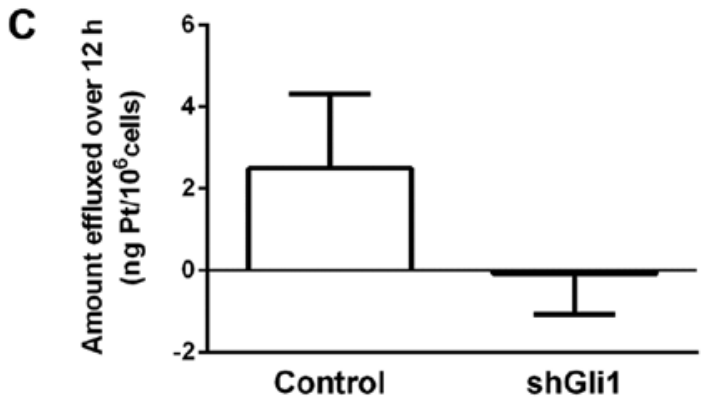

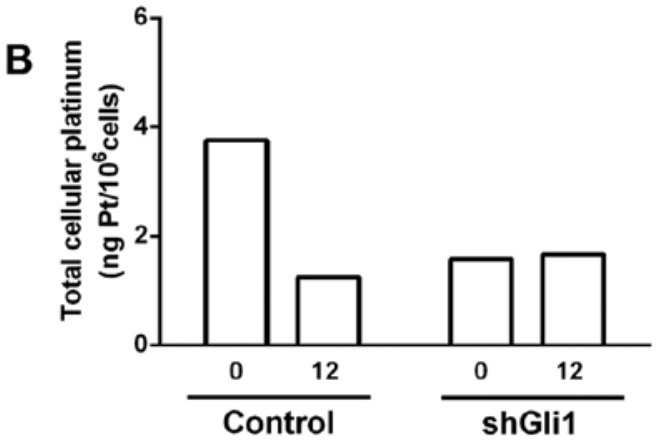

D

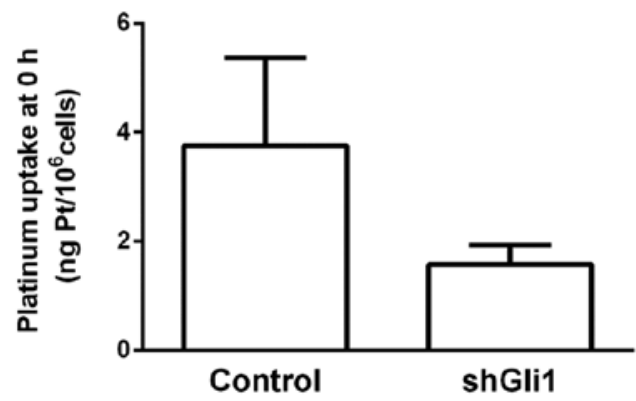

Figure 1. Cells treated with anti-Gli1 shRNA have reduced uptake and efflux of cisplatin, in comparison to control cells. A2780-CP70 cells were transfected with Gli1 or scrambled control shRNA for $24 \mathrm{~h}$. Cells were treated for $1 \mathrm{~h}$ with an $\mathrm{IC}_{50}$ dose of cisplatin, $30 \mu \mathrm{M}$. Time zero began immediately after the 1 -h cisplatin treatment to measure uptake. Cells were allowed to recover for $12 \mathrm{~h}$ to measure efflux. Cells were collected and whole cell platinum was measured by AAS. (A) Table of numerical results of the data, including means and standard deviations. (B) Total cellular platinum levels at time 0 and after the $12-\mathrm{h}$ recovery period. (C) Cellular platinum efflux after $12 \mathrm{~h}$. (D) Cellular platinum uptake results at time zero.

cells accumulated $3.75 \mathrm{ng} \mathrm{Pt} / 10^{6}$ cells, after a $1 \mathrm{~h}$ cisplatin exposure. Total cellular platinum was also measured $12 \mathrm{~h}$ after cisplatin was removed from cells. Total cellular platinum was reduced to $1.25 \mathrm{ng} \mathrm{Pt} / 10^{6}$ cells, indicating that these cells effluxed $2.5 \mathrm{ng} \mathrm{Pt} / 10^{6}$ cells over this 12 -h period. When cells were treated with anti-Gli1 shRNA, the platinum level at $0 \mathrm{~h}$ was $1.58 \mathrm{ng} \mathrm{Pt} / 10^{6}$ cells, which was essentially unchanged $12 \mathrm{~h}$ later, measured at $1.66 \mathrm{ng} \mathrm{Pt} / 10^{6}$ cells. This indicates that under control conditions, $67 \%$ of total cellular platinum was removed over $12 \mathrm{~h}$ (3.75 down to $1.25 \mathrm{ng}$ ). Furthermore, when cells were pretreated with anti-Gli1 shRNA, these cells were unable to efflux platinum over the same 12-h period. Fig. 1C graphically shows the differences with respect to total drug effluxed during the 12-h experiment.

Fig. 1D, graphically shows the differences between conditions with respect to the initial levels of total cellular platinum. When cells were pretreated with scrambled shRNA total cellular drug was 3.75 vs. 1.58 units when pretreated with antiGli1 shRNA; a 58\% reduction in drug uptake. This suggests that drug uptake was greatly reduced by the inhibition of Gli1.

Nuclear lysate recognizes the GBS of each of five platinum transport genes. We studied seven of 12 known platinum transport genes, for the possibility of harboring one or more Gli-binding sites in their 5'UTR. The genes we studied were CTR1, CTR2, ATP7A, ATP7B, OCT1, OCT2 and OCT3. Approximately $10 \mathrm{kB}$ upstream of each gene was obtained and searched for the binding sites using BLAST (http://blast.ncbi. nlm.nih.gov/Blast.cgi). For two of these seven genes, there was no indication of a GBS in the 5'UTR; CTR1 and ATP7B. For five genes that contained a GBS in the 5'UTR, those sequences are listed in Fig. 2A. Two of these genes, OCT1 and OCT3, have two GBS sites each, which are given in Fig. 2A.

We next assessed nuclear lysates from A2780-CP70 cells, for the ability to bind the synthesized Gli-binding sites for each of the platinum transporters listed in Fig. 2A. In Fig. 2B, we show the EMSAs for each GBS for each gene. The EMSA is run with the synthetic GBS mixed with nuclear lysate. The negative control, GBS alone, is run to check for gross abnormalities of the probe.

CTR2, OCT1, OCT2 and OCT3, are platinum influx proteins/genes. In each case the GBS probe demonstrated the predicted shift within the nuclear lysate lane. ATP7A is a platinum efflux protein/gene. In this case as well, the GBS probe demonstrated the predicted shift. Therefore, for each of the five genes studied, and a total of seven GBS probes, the nuclear lysate of these cells generated the predicted shift. This indicates that a GBS-binding protein exists in the nuclear lysate of these cells for each of these five platinum transport genes. As shown in Fig. 1, when Gli1 is disrupted by the use of anti-Gli1 shRNA, cellular influx of cisplatin is reduced and cellular efflux of cisplatin is abrogated.

Comparing cellular accumulation and DNA repair in the cells. We have extended the studies we previously performed with respect to the repair of platinum-DNA adducts. This is summarized in Fig. 3. As we have reported (1), the repair of platinum-DNA damage is greatly inhibited by using anti-Gli1 shRNA in these cells. Fig. 3A, gives the raw data from $n=4$. Fig. 3A-C show that under control conditions, $\sim 68 \%$ repair occurs for platinum-DNA damage over $12 \mathrm{~h}$. When cells are treated with anti-Gli1 shRNA, $24 \%$ repair occurs $(\mathrm{P}=0.015)$. 
A

\begin{tabular}{|c|c|}
\hline Gene & GBS \\
\hline CTR2 & 5'-AAATAAATTGGGTGGTCAGAGTGGC-3* \\
\hline OCT1 & $\begin{array}{c}\text { 5'-TCAGCCCTTGGGTGGTCGATGGGAC-3'* } \\
\text { 5'-GTCCATGCTGGTGGTCTTTACCA-3** }\end{array}$ \\
\hline OCT2 & 5'-TAAGTTCCTGGCTGCTCGGGGCACT-3"* \\
\hline OCT3 & $\begin{array}{l}\text { 5'-AACCGCAAGTCCTCCCAAGGCCTTG-3' } \\
\text { 5'-TCTGGGGGTGGGTGGTGGTTTATC-3** }\end{array}$ \\
\hline ATP7A & 5'-AATCGTATGAACACCCATATACCCA-3' \\
\hline
\end{tabular}
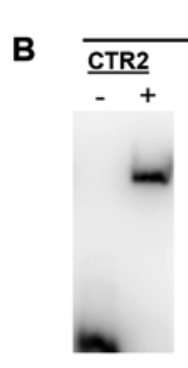

Uptake

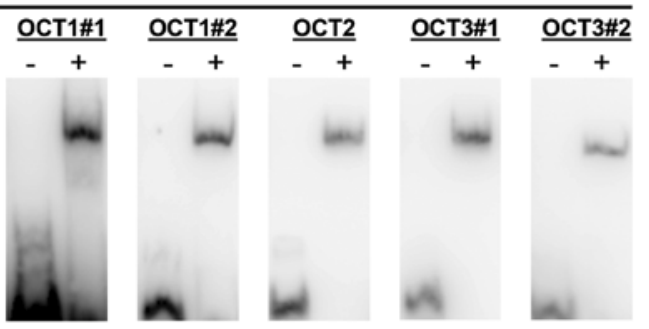

Efflux

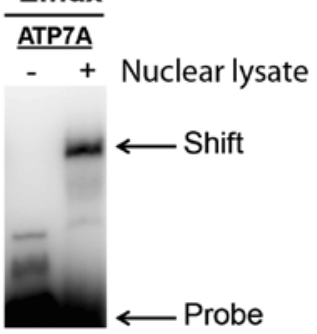

Figure 2. Nuclear lysate from A2780-CP70 cells bind the GBS found in cisplatin transporters. (A) Table displaying the platinum transporters and the GBS sequence, underlined, found in the 5'UTR. A reverse compliment GBS is indicated by an asterisk. In each case the eight base pair sequence that flanks the GBS in that specific gene is listed. This was incorporated in the synthesized probe. (B) EMSAs were performed to assess if a nuclear lysate protein binds the GBS identified in the cisplatin transporters listed in (A). Each GBS was analyzed using a negative control (-), which contains the biotin-labeled oligonucleotide probe and no nuclear lysate. The positive control (+), contains A2780-CP70 nuclear lysate with the biotin-labeled GBS of the respective transporter; showing the resultant shift. All transporter EMSAs exhibited a shift in the positive control suggesting a Gli protein binds the GBS.

A

\begin{tabular}{|c|c|c|c|c|c|c|c|}
\hline & \multicolumn{3}{|c|}{ Percent repair at $12 \mathrm{~h}$} & \multirow[b]{2}{*}{$\# 4$} & \multirow[b]{2}{*}{ Mean } & \multirow[b]{2}{*}{ STD Dev } & \multirow[b]{2}{*}{ T-Test } \\
\hline & $\#$ \#1 & $\# 2$ & $\# 3$ & & & & \\
\hline Scramble & 83 & 86 & 51 & 50 & 68 & 19.7 & 0.015 \\
\hline \multirow[t]{4}{*}{ shGli1 } & 12 & 49 & 20 & 14 & 24 & 17.2 & \\
\hline & & & & & & & \\
\hline & \multicolumn{5}{|c|}{ Pt-DNA adduct level at time $0(\mathrm{pg}$ PT/ $\mu \mathrm{g}$ DNA) } & & \\
\hline & \#1 & $\# 2$ & 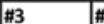 & $\# 4$ & Mean & STD Dev & T-test \\
\hline Scramble & 5.67 & 6.51 & 2.80 & 4.03 & 4.75 & 1.66 & 0.792 \\
\hline \multirow[t]{4}{*}{ shGli1 } & 2.21 & 6.11 & 3.79 & 5.56 & 4.42 & 1.77 & \\
\hline & & & & & & & \\
\hline & \multicolumn{4}{|c|}{ Pt-DNA adduct level at $12 \mathrm{~h}$} & & & \\
\hline & \#1 & $\# 2$ & \#3 & \#4 & Mean & STD Dev & T-Test \\
\hline Scramble & 0.98 & 0.93 & 1.38 & 2.02 & 1.33 & 0.50 & 0.024 \\
\hline \multirow[t]{4}{*}{ shGli1 } & 1.95 & 3.09 & 3.09 & 4.79 & 3.23 & 1.17 & \\
\hline & & & & & & & \\
\hline & \multicolumn{3}{|c|}{ Amount repaired at $12 \mathrm{~h}$} & & & & \\
\hline & \#1 & \#2 & $\# 3$ & \#4 & Mean & STD Dev & T-Test \\
\hline Scramble & 4.69 & 5.58 & 1.42 & 2.01 & 3.43 & 2.02 & 0.108 \\
\hline \multirow[t]{4}{*}{ shGli1 } & 0.26 & 3.02 & 0.70 & 0.77 & 1.19 & 1.24 & \\
\hline & & & & & & & \\
\hline & \multicolumn{4}{|c|}{$\%$ of baseline level of DNA damage } & & & \\
\hline & \#1 & \#2 & \begin{tabular}{|l|l}
$\# 3$ & \\
\end{tabular} & & Mean & STD Dev & T-Test \\
\hline Scramble & 17 & 14 & 49 & 50 & 33 & 19.7 & 0.015 \\
\hline shGli1 & 88 & 51 & 82 & 86 & 77 & 17.3 & \\
\hline
\end{tabular}

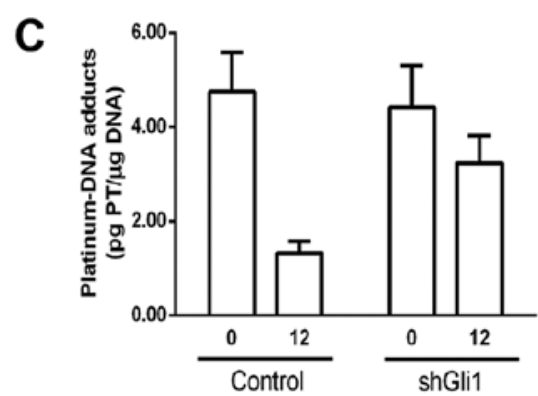

B

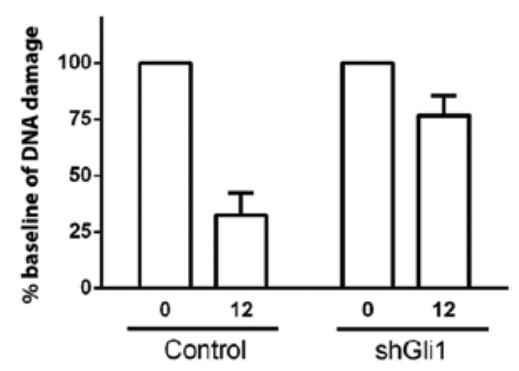

D

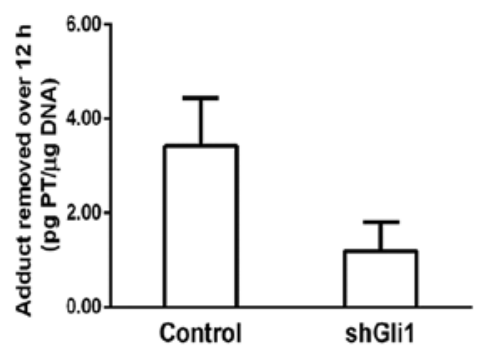

Figure 3. Repair of DNA-platinum adducts is inhibited in cells treated with Gli1 shRNA. A2780-CP70 cells were treated for $24 \mathrm{~h}$ with anti-Gli1 or scrambled control shRNA. Cells were then treated with an $\mathrm{IC}_{50}$ dose of cisplatin $(30 \mu \mathrm{M})$ for $1 \mathrm{~h}$. Cells were collected and DNA was isolated to measure DNA-platinum adducts at time 0 (immediately after cisplatin treatment) and $12 \mathrm{~h}$ later. (A) Table listing all numerical data of DNA-platinum adduct experiments. (B) Graph of percent baseline of DNA damage. (C) Graph of platinum-DNA adducts at time 0 and $12 \mathrm{~h}$. (D) Graph of platinum-DNA adducts removed over the 12-h period. Cells treated with anti-Gli1 shRNA display reduced levels of DNA repair in comparison to controls. 


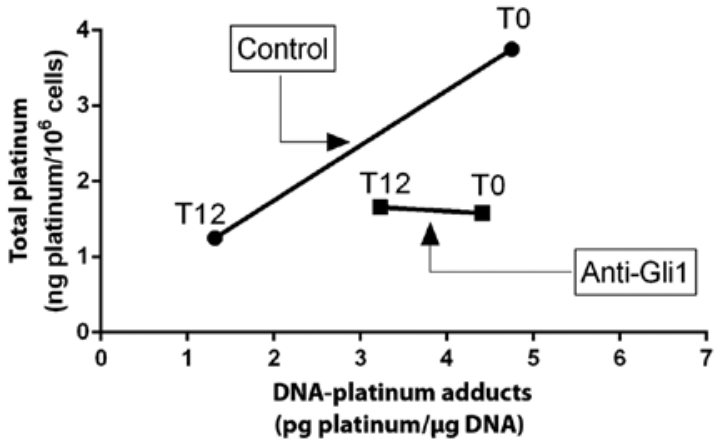

Figure 4. Comparison of DNA damage with whole cell platinum levels in A2780-CP70 cells treated with Glil shRNA. Total platinum-DNA damage is plotted against total cellular platinum at time zero (immediately after the 1-h cisplatin exposure) and at $12 \mathrm{~h}$. This is done for shRNA scrambled controls; and for anti-Gli1 shRNA treated cells. Cells treated with Gli1 shRNA display similar levels of DNA-platinum adduct at time zero as do control cells, although drug uptake is reduced. After the 12-h recovery period, Gli1 shRNA treated cells show no change in total cellular platinum and only a $23 \%$ repair of the DNA-platinum adducts. Control cells effluxed $67 \%$ of the total cellular platinum and repaired $68 \%$ of the DNA-platinum adducts. Glil is, therefore, involved in three molecular processes: DNA repair, drug accumulation and drug efflux.

Fig. 3A and D, show that the absolute amount of DNA adduct repaired over the 12-h time frame, is $\sim 3$-fold greater under control conditions, as compared to when Gli1 is inhibited (3.43 vs. 1.19 units).

We next sought to compare these two experimental conditions, in a manner where total cellular drug and total DNA damage could be assessed concurrently, at $0 \mathrm{~h}$ and at $12 \mathrm{~h}$. This is graphically shown in Fig. 4. Here, total cellular platinum is plotted on the vertical axis, and total DNA damage is assessed on the horizontal axis. Cells treated under control conditions are plotted at $0 \mathrm{~h}$ and at $12 \mathrm{~h}$. Cells treated with anti-Glil shRNA are plotted at $0 \mathrm{~h}$ and at $12 \mathrm{~h}$.

Fig. 4 shows is that at time zero (immediately after the 1-h exposure to cisplatin), cells treated with anti-Gli1 shRNA had less than half the total cellular platinum than control cells treated at the same cisplatin dose. This illustrates that inhibition of Gli1, in this manner, greatly inhibits cisplatin uptake in these cells. Also of interest, is that at this $\mathrm{IC}_{50}$ cisplatin dose, the total amount of DNA damage experienced by these cells is almost exactly the same, 4.5 units. This is consistent with previous reports of the relationships between DNA damage levels and cisplatin $\mathrm{IC}_{50}$ values in other cell lines $(5,14)$.

Also shown in Fig. 4, under control conditions, reductions in total cellular levels of drug and removal of DNA damage, appear to be phenotypically linked. In contrast, in cells where Gli1 is inhibited, DNA repair continues to a limited degree although cellular efflux of drug is frozen. Previous studies from this group suggest that in these cells, DNA repair and cellular accumulation of drug may be linked processes (5). It appears from Fig. 4, that this linkage can be disrupted through inhibition of Gli1.

\section{Discussion}

Cellular resistance to cisplatin has been associated with the phenotypic linkage of DNA repair and cellular accumulation of drug, since the mid-1980s. Eastman was the first to show in a cellular system, that for levels of cisplatin resistance to $\sim 10$-fold over baseline, these two molecular processes go hand-in-hand (15-17). The consensus belief is that this level of resistance was probably the range that was clinically relevant to human patients (18). Parker and colleagues were the first to show that in human ovarian cancer cells, levels of resistance up to $\sim 13$-fold over baseline were associated with phenotypic linkage of DNA repair and cellular accumulation of drug (5). This was also observed in human T lymphocyte cell lines (19). Masuda et al (20) and Ferry and colleagues (21) confirmed in a series of studies in human ovarian cancer cells, that at this level of resistance, DNA repair was very important. They also showed that at levels of resistance in the range above 30-fold over baseline, cytosolic inactivation of drug appeared to become the predominant molecular mechanism of cisplatin resistance $(22,23)$.

In the present study we report on the A2780-CP70 cell line, where these two processes are linked. Here, we show that Gli1 appears to be an important common molecular entity that controls cellular uptake of drug and cellular efflux of drug. Previously we showed that Gli1 is critical to platinum-DNA repair.

Enhanced DNA repair is associated with cisplatin resistance. The involvement of Gli1 in DNA damage and repair pathways has been reported by several groups $(1,24,25)$. Mazumdar and colleagues demonstrated that inhibition of Gli1 using small molecule inhibitors induces double strand DNA breaks (DSBs) coupled with reduced DNA repair in colon cancer $(26,27)$. Leonard and colleagues demonstrated increased expression of Gli1 in HEK293 cells resulted in the inability to activate Chk1 after ionizing radiation (25).

Our group has identified the importance of Gli1 in the regulation of nucleotide excision repair and base excision repair in response to platinum DNA damage (1). Gli1 shRNA treated cells exhibited a switch in the c-jun phosphorylation cascade, from a pro-survival to a pro-apoptotic pattern. In response to cisplatin treatment, the upregulation of DNA repair genes by c-jun is blocked and cells are unable to repair platinum-DNA lesions.

Our laboratory identified the isoform of Gli1, the $130-\mathrm{kDa}$ isoform, responsible for upregulating c-jun (28). Gli1 has 5 known isoforms: full-length, two mRNA splice variants, and two post-translational truncations of the full-length protein. The $130-\mathrm{kDa}$ Gli1 isoform is generated by an N-terminal truncation of the full-length protein resulting in the removal of the N-terminal Degron domain and the Sufu-binding domain. Ovarian cancer specimens express higher levels of the $130-\mathrm{kDa}$ isoform in comparison to non-cancer specimens. Additionally, the $130-\mathrm{kDa}$ isoform was expressed at higher levels in the cisplatin resistant cell lines A2780-CP70 and A2780-CIS when compared with the parental cell line A2780. This opens the possibility that the Gli1 $130-\mathrm{kDa}$ isoform may play a role in both components of cisplatin drug resistance; i.e., DNA repair and cellular accumulation of drug.

There are a large number of genes/proteins associated with platinum transport across cellular membranes. This has been reviewed by Hall et al (8). Many of these genes have been shown to be highly conserved, with analogs that exist in grapes (29), rice (30), barley (31) and a range of vertebrates. In 
humans, these genes tend to be highly expressed in kidney, in the inner ear, and in various tissues throughout the body (8). In the present study, we focused on those transporters where there is a Gli-binding site in the 5'UTR of that specific gene. For these transporters (Fig. 2), there exists the possibility that Glil may have direct impact on the regulation of those genes.

We further analyzed the 5'UTR of these genes for binding sites for other regulatory proteins. For the transporters we examined, we could find binding sites for either: Gli, c-jun or AP1 (data not shown). We have previously demonstrated that Gli1 effects changes in cisplatin-DNA adduct repair through its influence on c-jun (1). c-jun heterodimerizes with c-fos to form the transcriptionally active AP1 (32). This suggests that when Glil is inhibited by using anti-Gli1 shRNA, there may also be a strong indirect effect on the regulation of some cisplatin transporters, through Glil's modulation of c-jun or AP1.

\section{Acknowledgements}

The present research was supported by the Intramural Research Program of the NIH, National Institute on Minority Health and Health Disparities.

\section{References}

1. Kudo K, Gavin E, Das S, Amable L, Shevde LA and Reed E: Inhibition of Gli1 results in altered c-Jun activation, inhibition of cisplatin-induced upregulation of ERCC1, XPD and XRCC1, and inhibition of platinum-DNA adduct repair. Oncogene 31: 4718-4724, 2012.

2. Steg AD, Bevis KS, Katre AA, et al: Stem cell pathways contribute to clinical chemoresistance in ovarian cancer. Clin Cancer Res 18: 869-881, 2012.

3. Ulasov IV, Nandi S, Dey M, Sonabend AM and Lesniak MS: Inhibition of Sonic hedgehog and Notch pathways enhances sensitivity of $\mathrm{CD}_{133^{+}}$glioma stem cells to temozolomide therapy. Mol Med 17: 103-112, 2011.

4. Reed E: Cisplatin, carboplatin and oxaliplatin. In: Cancer Chemotherapy and Biotherapy: Principles and Practice. 4th edition. Chabner BA and Longo DL (eds). Lippincott Williams and Wilkins, Philadelphia, pp332-343, 2006.

5. Parker RJ, Eastman A, Bostick-Bruton F and Reed E: Acquired cisplatin resistance in human ovarian cancer cells is associated with enhanced repair of cisplatin-DNA lesions and reduced drug accumulation. J Clin Invest 87: 772-777, 1991.

6. Reed E: Cisplatin and platinum analogs. In: Cancer Principles and Practice of Oncology. 8th edition. DeVita VT, Rosenberg SA and Lawrence T (eds). Lippincott Williams and Wilkins, Philadelphia, pp419-426, 2008.

7. Reed E and Chabner BA: Platinum analogues. In: Cancer Chemotherapy and Biotherapy: Principles and Practice. 5th edition. Chabner BA and Longo DL (eds). Lippincott Williams and Wilkins, Philadelphia, pp310-322, 2011.

8. Hall MD, Okabe M, Shen DW, Liang XJ and Gottesman MM: The role of cellular accumulation in determining sensitivity to platinum-based chemotherapy. Annu Rev Pharmacol Toxicol 48: 495-535, 2008.

9. Reed E, Sauerhoff S and Poirier MC: Quantitation of platinumDNA binding in human tissues following therapeutic levels of drug exposure: a novel use of graphite furnace spectrometry. Atomic Spectroscopy 9: 93-95, 1988.

10. Laner-Plamberger S, Kaser A, Paulischta M, HauserKronberger C, Eichberger T and Frischauf AM: Cooperation between GLI and JUN enhances transcription of JUN and selected GLI target genes. Oncogene 28: 1639-1651, 2009.
11. Zhu $\mathrm{H}$ and Lo HW: The human glioma-associated oncogene homolog 1 (GLI1) family of transcription factors in gene regulation and diseases. Curr Genomics 11: 238-245, 2010.

12. Hess J, Angel P and Schorpp-Kistner M: AP-1 subunits: quarrel and harmony among siblings. J Cell Sci 117: 5965-5973, 2004.

13. Stein B, Angel P, van Dam H, et al: Ultraviolet-radiation induced c-jun gene transcription: two AP-1 like binding sites mediate the response. Photochem Photobiol 55: 409-415, 1992.

14. Lee KB, Parker RJ, Bohr V, Cornelison T and Reed E: Cisplatin sensitivity/resistance in UV repair-deficient Chinese hamster ovary cells of complementation groups 1 and 3. Carcinogenesis 14: 2177-2180, 1993.

15. Richon VM, Schulte N and Eastman A: Multiple mechanisms of resistance to cis-diamminedichloroplatinum(II) in murine leukemia L1210 cells. Cancer Res 47: 2056-2061, 1987.

16. Eastman A and Schulte N: Enhanced DNA repair as a mechanism of resistance to cis-diamminedichloroplatinum(II). Biochemistry 27: 4730-4734, 1988.

17. Eastman A: Mechanisms of resistance to cisplatin. Cancer Treat Res 57: 233-249, 1991.

18. Reed E: Cisplatin. In: Cancer Chemotherapy and Biological Response Modifiers. Pinedo H, Longo D and Chabner B (eds). Elsevier Science, Amsterdam, pp83-90, 1992.

19. Dabholkar M, Parker R and Reed E: Determinants of cisplatin sensitivity in non-malignant non-drug-selected human $\mathrm{T}$ cell lines. Mutat Res 274: 45-56, 1992.

20. Masuda H, Ozols RF, Lai GM, Fojo A, Rothenberg M and Hamilton TC: Increased DNA repair as a mechanism of acquired resistance to cis-diamminedichloroplatinum (II) in human ovarian cancer cell lines. Cancer Res 48: 5713-5716, 1988.

21. Ferry KV, Hamilton TC and Johnson SW: Increased nucleotide excision repair in cisplatin-resistant ovarian cancer cells: role of ercc1-xpf. Biochem Pharmacol 60: 1305-1313, 2000.

22. Godwin AK, Meister A, O'Dwyer PJ, Huang CS, Hamilton TC and Anderson ME: High resistance to cisplatin in human ovarian cancer cell lines is associated with marked increase of glutathione synthesis. Proc Natl Acad Sci USA 89: 3070-3074, 1992.

23. Yao KS, Godwin AK, Johnson SW, Ozols RF, O'Dwyer PJ and Hamilton TC: Evidence for altered regulation of gamma-glutamylcysteine synthetase gene expression among cisplatin-sensitive and cisplatin-resistant human ovarian cancer cell lines. Cancer Res 55: 4367-4374, 1995.

24. Agyeman A, Mazumdar T and Houghton JA: Regulation of DNA damage following termination of Hedgehog $(\mathrm{HH})$ survival signaling at the level of the GLI genes in human colon cancer. Oncotarget 3: 854-868, 2012.

25. Leonard JM, Ye H, Wetmore C and Karnitz LM: Sonic Hedgehog signaling impairs ionizing radiation-induced checkpoint activation and induces genomic instability. J Cell Biol 183: 385-391, 2008.

26. Mazumdar T, Devecchio J, Agyeman A, Shi T and Houghton JA: Blocking Hedgehog survival signaling at the level of the GLI genes induces DNA damage and extensive cell death in human colon carcinoma cells. Cancer Res 71: 5904-5914, 2011.

27. Mazumdar T, DeVecchio J, Agyeman A, Shi T and Houghton JA: The GLI genes as the molecular switch in disrupting Hedgehog signaling in colon cancer. Oncotarget 2: 638-645, 2011.

28. Amable L, Gavin E, Kudo K, et al: Gli1 upregulates c-jun through a specific $130 \mathrm{kDa}$ isoform. Int $\mathrm{J}$ Oncol (In press).

29. Martins V, Hanana M, Blumwald E and Geros H: Copper transport and compartmentation in grape cells. Plant Cell Physiol 53: 1866-1880, 2012.

30. Takahashi R, Bashir K, Ishimaru Y, Nishizawa NK and Nakanishi H: The role of heavy-metal ATPases, HMAs, in zinc and cadmium transport in rice. Plant Signal Behav 7: 1605-1607, 2012.

31. Mikkelsen MD, Pedas P, Schiller M, et al: Barley HvHMA1 is a heavy metal pump involved in mobilizing organellar $\mathrm{Zn}$ and $\mathrm{Cu}$ and plays a role in metal loading into grains. PLoS One 7: e49027, 2012.

32. Li Q, Gardner K, Zhang L, Tsang B, Bostick-Bruton F and Reed E: Cisplatin induction of ERCC-1 mRNA expression in A2780/CP70 human ovarian cancer cells. J Biol Chem 273: 23419-23425, 1998. 